\title{
Flash-evaporation printing methodology for perovskite thin films
}

\author{
Haoming Wei ${ }^{1,2,4}$, Xingyue Zhao ${ }^{2,4}$, Yang Wei ${ }^{1,4}, \mathrm{He} \mathrm{Ma}^{1}$, Dongqi $\mathrm{Li}^{1}$, Guo Chen ${ }^{1}$, Hong $\mathrm{Lin}^{2}$, \\ Shoushan Fan ${ }^{1,2,3}$ and Kaili Jiang ${ }^{1,3}$
}

Printing solutions have attracted wide attention from various research fields, but thin films made by printing technologies still cannot match the quality of the films made by conventional thin-film deposition methods. In this study, a flash-evaporation printing (FEP) technology, which employed a freestanding carbon nanotube (CNT) flash evaporator, was developed to address this issue and to achieve a compact physical vapor deposition geometry. The target material precoated on the CNT flash evaporator was printed onto a substrate by gas-phase transportation. The FEP methodology presented a printable solution for hybrid perovskite thin films. The as-fabricated photovoltaic devices showed power conversion efficiencies of $\sim 10.3 \%$, and the thin films were also utilized as potential photodetectors. In addition, this technology can also be used to print patterns and a wide variety of materials on large panels. The environmentally friendly and cost-effective FEP technology will be of significant benefit to printed electronics, organic electronics and future flexible electronics.

NPG Asia Materials (2017) 9, e395; doi:10.1038/am.2017.91; published online 30 June 2017

\section{INTRODUCTION}

For centuries, printing has been improving social civilization, from Gutenberg's printing press to today's state-of-the-art printing industry. Printing methodologies evolved into printed electronics when microelectronics were developed, making integrated circuits printable, flexible and cheaper. Printed electronics use printable paste and ink made from functional materials with complex recipes. ${ }^{1-11}$ Thus, the quality of printed films usually cannot be compared with thin films made by conventional physical vapor deposition (PVD) methods because of the high purity of the vapor source generated from the target in vacuum in PVD processes. This suggests that a great improvement of printed electronics is possible by integrating vacuum PVD procedures into printing processes.

Here, we propose a flash-evaporation printing (FEP) methodology that successfully combines a compact PVD process with printed electronics. The success is attributed to the flash evaporator made by cross-stacked superaligned carbon nanotube (CNT) films resulting in a fast high-temperature response. ${ }^{12-14}$ The evaporator is $\sim 1.5 \mu \mathrm{m}$ in thickness, and the heat capacity per unit area (HCPUA) is only $\sim 0.1 \mathrm{~J} \mathrm{~m}^{-2} \mathrm{~K}^{-1}$, over 3 orders of magnitude lower than metal heaters used in conventional thermal evaporation. A flash-evaporation transfer ribbon was developed by coating a target material on the evaporator.
The printing of the target material was conducted by the gas-phase transportation from the hot CNT evaporator stimulated by laser irradiation to the cold substrate below. The CNT evaporator, the facile transfer ribbon and the compact geometry promote the invariable flash evaporation that was implemented in a large thermal-evaporation facility to a different and new printing methodology. ${ }^{15-17}$

Organic-inorganic hybrid perovskites, such as $\mathrm{CH}_{3} \mathrm{NH}_{3} \mathrm{PbI}_{3}$ $\left(\mathrm{MAPbI}_{3}\right)$, have recently captured intense research interest for their promising optoelectronic applications with low cost and high performance. ${ }^{18-29}$ A two-step deposition ${ }^{30}$ is the common route to synthesize perovskite thin films. In this process, lead iodide $\left(\mathrm{PbI}_{2}\right)$ is first introduced using solution or vapor deposition methods and is subsequently transformed into the perovskite by reacting with $\mathrm{CH}_{3} \mathrm{NH}_{3} \mathrm{I}$ (methylammonium iodide (MAI)). Typically, the as-formed compact $\mathrm{PbI}_{2}$ layer blocks MAI penetration and diffusion into the deeper $\mathrm{PbI}_{2}$ layer, resulting in the incomplete transformation of $\mathrm{PbI}_{2}$ to the perovskite. ${ }^{31}$ Several strategies have been developed to solve this problem, such as incorporating a small amount of $\mathrm{MAI}^{32}$ or additive ${ }^{33}$ into the precursor solution, producing a porous $\mathrm{PbI}_{2}$ nanostructured layer by solvent engineering, ${ }^{31,34}$ using $\mathrm{PbI}_{2} / \mathrm{MAI}$ multilayer stacks ${ }^{35}$ and others. ${ }^{36}$ However, fabricating perovskite thin films with a printing methodology is also an emerging trend. ${ }^{37,38}$ Here, the new

\footnotetext{
${ }^{1}$ State Key Laboratory of Low-Dimensional Quantum Physics, Department of Physics and Tsinghua-Foxconn Nanotechnology Research Center, Tsinghua University, Beijing, China; ${ }^{2}$ State Key Laboratory of New Ceramics and Fine Processing, School of Materials Science and Engineering, Tsinghua University, Beijing, China and ${ }^{3}$ Collaborative Innovation Center of Quantum Matter, Beijing, China

${ }^{4}$ These authors contributed equally to this work.

Correspondence: Professor Y Wei, Tsinghua-Foxconn Nanotechnology Research Center, Tsinghua University, Beijing 100084, China.

E-mail: WeiYang@tsinghua.edu.cn

or Professor H Lin, State Key Laboratory of New Ceramics and Fine Processing, School of Materials Science and Engineering, Tsinghua University, Beijing 100084, China.

E-mail: hong-lin@tsinghua.edu.cn

or Professor K Jiang, Collaborative Innovation Center of Quantum Matter, Beijing 100084, China.

E-mail: JiangKL@tsinghua.edu.cn

Received 22 December 2016; revised 10 April 2017; accepted 10 April 2017
} 
FEP methodology was used to fabricate $\mathrm{MAPbI}_{3}$ perovskite thin films. Nanoporous $\mathrm{PbI}_{2}$ thin films were directly printed on substrates as precursors by FEP, and then high-quality perovskite thin films were produced by an in situ reaction with an MAI solution. The properties and morphology of the as-prepared films were shown to be satisfactory by X-ray diffraction (XRD), ultraviolet-visible (UV-Vis) absorption spectroscopy and scanning electron microscopy (SEM). To further reveal the potential of the FEP technique, perovskite thin films were integrated into photovoltaic devices that exhibited power conversion efficiencies (PCEs) of $\sim 10.3 \%$, and these films were also utilized to make photodetectors. Furthermore, this distinctive printing method is competent for patterning and is environmentally friendly and cost effective. The FEP technique will prove itself applicable to a wide variety of materials and will be a great impetus to printable electronics and flexible electronics.

\section{MATERIALS AND METHODS}

\section{Materials}

Unless specified otherwise, all materials were purchased from either Alfa Aesar (Ward Hill, MA, USA) or Sigma-Aldrich (St Louis, MO, USA). MAI was purchased from Dyesol (Queanbeyan, NSW, Australia).

\section{Fabrication of the flash-evaporation transfer ribbon}

CNT films, used as building blocks for the flash evaporator, were dry spun from superaligned CNT arrays synthesized on silicon wafers by low-pressure chemical vapor deposition. ${ }^{39,40} \mathrm{~A}$ cross-stacked CNT sheet with 15 single layers was coated onto a $25 \times 25 \mathrm{~mm}^{2}$ metal frame. After stacking, the CNT sheet was dipped in ethanol and dried in air at room temperature to make the CNTs compact. A $\mathrm{PbI}_{2}$ solution made of $1.3 \mathrm{M} \mathrm{PbI}_{2}$ precursor in anhydrous dimethylformamide and dimethylsulfoxide $(17: 3, \mathrm{v} / \mathrm{v})$ was then deposited onto the CNT sheet by spin-coating. The transfer ribbon was made by dropping $100 \mu \mathrm{l}$ of the $\mathrm{PbI}_{2}$ solution onto the CNT sheet mounted on a sample holder and then spinning at 2000 r.p.m. for 30 s. During the formation of the $\mathrm{PbI}_{2}$ film precursor, the transfer ribbon was heated to $100^{\circ} \mathrm{C}$ for $10 \mathrm{~min}$ to remove the solvents. Notably, the transfer ribbon can be scaled up using larger CNT evaporators, as the mass production of a superaligned CNT array on an 8 inch wafer has been realized, and $\sim 200 \mathrm{~m}$-long CNT thin films can be spun from each wafer. ${ }^{40}$ After the fabrication, a flash-evaporation transfer ribbon was placed on top of a substrate with a gap of $1 \mathrm{~mm}$, as shown in the schematic diagram of the FEP (Figure 1a). A sample holder was employed to set the substrate and the transfer ribbon that can be seen in the compact FEP chamber (Supplementary Figure S1).

\section{Temperature measurement of the hot CNT flash evaporator}

The spectra of the hot CNT flash evaporator were recorded by a spectrometer (Konica Minolta CS-1000, Tokyo, Japan), and the temperature was derived by fitting the spectra with the blackbody radiation law, as we previously reported. ${ }^{41,42}$ The variation of the laser-power-dependent heating temperature is shown in Supplementary Figure S2.

\section{Photovoltaic device fabrication}

Devices were fabricated on fluorine-doped tin oxide (FTO)-coated glass (Nippon Sheet Glass Co., Ltd, Tokyo, Japan). Initially, FTO was removed from the region under the anode contact area by etching the FTO with $2 \mathrm{M} \mathrm{HCl}$ and zinc powder. The substrates were then cleaned sequentially in soap, deionized water, ethanol, acetone, isopropanol and oxygen plasma. A compact layer of titanium dioxide $\left(\mathrm{TiO}_{2}\right)$ was subsequently deposited by spin-coating a mildly acidic solution of titanium isopropoxide in ethanol at 2000 r.p.m. for $60 \mathrm{~s}$ and annealing at $50{ }^{\circ} \mathrm{C}$ for $30 \mathrm{~min}$. Then, $80 \mu \mathrm{l}$ of a PCBM ([6,6]-phenylC61-butyric acid methyl ester) solution $\left(10 \mathrm{mg} \mathrm{ml}^{-1}\right)$ was spin-coated on the top of $\mathrm{TiO}_{2}$ at 4000 r.p.m. for $40 \mathrm{~s}$ in a glovebox. The $\mathrm{PbI}_{2}$ film was printed on the $\mathrm{PCBM} / \mathrm{TiO}_{2}$ substrate via the FEP process. After $\mathrm{PbI}_{2}$ deposition, the samples were transferred into a glovebox for further processing. The perovskite layer was obtained by dipping the $\mathrm{PbI}_{2}$ precursor into an MAI solution (10 mg MAI in per $\mathrm{ml}$ isopropyl alcohol) for $10 \mathrm{~min}$ and drying at $100^{\circ} \mathrm{C}$ for
$30 \mathrm{~min}$. The hole-transport layer was deposited by spin-coating $2,2^{\prime}, 7,7^{\prime}$-tetrakis ( $N, N$-di(4-methoxyphenyl)amino)-9,9'-spirobifluorene (Spiro-OMeTAD) in chlorobenzene solution with added tert-butylpyridine and lithium bis(trifluoromethanesulfonyl)imide. The manufacturing process of the device was completed by thermally evaporating $\mathrm{Au}$ as the back electrode.

\section{Characterization}

The quality and morphology of the thin films were characterized by XRD (Rigaku D/max-2500/PC, Tokyo, Japan), UV-Vis absorption spectroscopy (Perkin Elmer Lambda 950, Waltham, MA, USA) and SEM (FEI Sirion 200, operated at $10 \mathrm{kV}$, Hillsboro, OR, USA). The current-voltage characteristics of the solar cells were recorded under AM $1.5 \mathrm{G} 100 \mathrm{~mW} \mathrm{~cm}^{-2}$ simulated sunlight (Newport Oriel 92192, Irvine, CA, USA) with a Keithley 2400 sourcemeter (Solon, OH, USA), previously calibrated with a calibrated Si solar cell. The solar cells were masked with a metal aperture defining the active area $\left(0.06 \mathrm{~cm}^{2}\right)$ of the devices. The incident photon-to-current efficiency (IPCE) spectra were characterized using a QEX10 solar cell quantum efficiency measurement system (QEX10, PV Measurements, Boulder, CO, USA). The photocurrent signal of the photodetector was measured using an Agilent (Santa Clara, CA, USA) B2902A sourcemeter by illuminating the device through a $0.2 \mathrm{~cm}^{2}$ aperture with a xenon lamp (AuLight, CEL-HXF300, Beijing, China) filtered by a bandpass filter of $530 \mathrm{~nm}$. The power was measured with a calibrated Thorlabs (Newton, NJ, USA) PM100D power meter. The response speed was surveyed by illuminating the device with a supercontinuum white-light source (NKT Photonics, Birkerød, Denmark, SuperK Compact), and the photocurrent was recorded with a Tektronix (Beaverton, OR, USA) oscilloscope (TDS2012C).

\section{RESULTS AND DISCUSSION}

The FEP technology is illustrated in Figure 1a, and a photograph of the experimental setup is shown in Supplementary Figure S1. A flash-evaporation transfer ribbon with $\mathrm{PbI}_{2}$ coated on CNT film-based evaporator was set on top of a substrate with a $1 \mathrm{~mm}$ gap. A picture of the $25 \times 25 \mathrm{~mm}^{2}$ freestanding CNT sheet is shown in Figure 1b, and Figure 1c provides an optical micrograph. The HCPUA and the thickness of the CNT evaporator were $\sim 0.1 \mathrm{~J} \mathrm{~m}^{-2} \mathrm{~K}^{-1}$ and $1.5 \mu \mathrm{m}$, respectively, that were calculated from the data of a singlelayer CNT film $\left(0.0077 \mathrm{~J} \mathrm{~m}^{-2} \mathrm{~K}^{-1}\right.$ and $100 \mathrm{~nm}$ per layer $){ }^{12}$ The HCPUA and the thickness are much smaller than those of a conventional metal heater in a thermal evaporator; for example, the tantalum heater used in the study of Longo et al. ${ }^{17}$ was $117 \mathrm{~J} \mathrm{~m}^{-2} \mathrm{~K}^{-1}$ and $100 \mu \mathrm{m}$ in thickness. The ultrasmall HCPUA and thickness are endowed by the unique CNT material and can hardly be achieved by conventional materials, ensuring the feasibility of the FEP. The flashevaporation transfer ribbon is shown in Figure 1d (optical micrograph) and Figure 1e (SEM image). The base pressure of the process chamber was $\sim 10^{-3}$ mbar. Because the CNT evaporator is black, as shown in Figure 1b, the yttrium aluminum garnet laser with a wavelength of $1.06 \mu \mathrm{m}$ was employed as a stimulus. The laser beam scanned the transfer ribbon with a speed of $1 \mathrm{~m} \mathrm{~s}^{-1}$ through a quartz window. The laser spot was $\sim 1 \mathrm{~mm}$ in diameter, and the pitch of the scanning lines was $100 \mu \mathrm{m}$. The temperature of the laser-heated flash evaporator can be modulated by the laser power, as shown in Supplementary Figure S2, and the optimized power was $12 \mathrm{~W}$ for printing the $\mathrm{PbI}_{2}$ precursor film. The CNT evaporator can be heated to $\sim 1100{ }^{\circ} \mathrm{C}$ instantaneously because of its ultrasmall heat capacity. Then, flash evaporation can start immediately, and gas-phase $\mathrm{PbI}_{2}$ can be transported from the transfer ribbon to the substrate. It takes only $\sim 4$ s to print a $20 \times 20 \mathrm{~mm}^{2} \mathrm{PbI}_{2}$ film. More experiments showed that the thicknesses of the printed $\mathrm{PbI}_{2}$ films could be well controlled by the amount of $\mathrm{PbI}_{2}$ spin-coated on the CNT films (Supplementary Figure S3). Figure 1f shows the morphology of the transfer ribbon after flash evaporation, revealing a very clean surface without $\mathrm{PbI}_{2}$ residue, suggesting that the flash-evaporation process is efficient. 

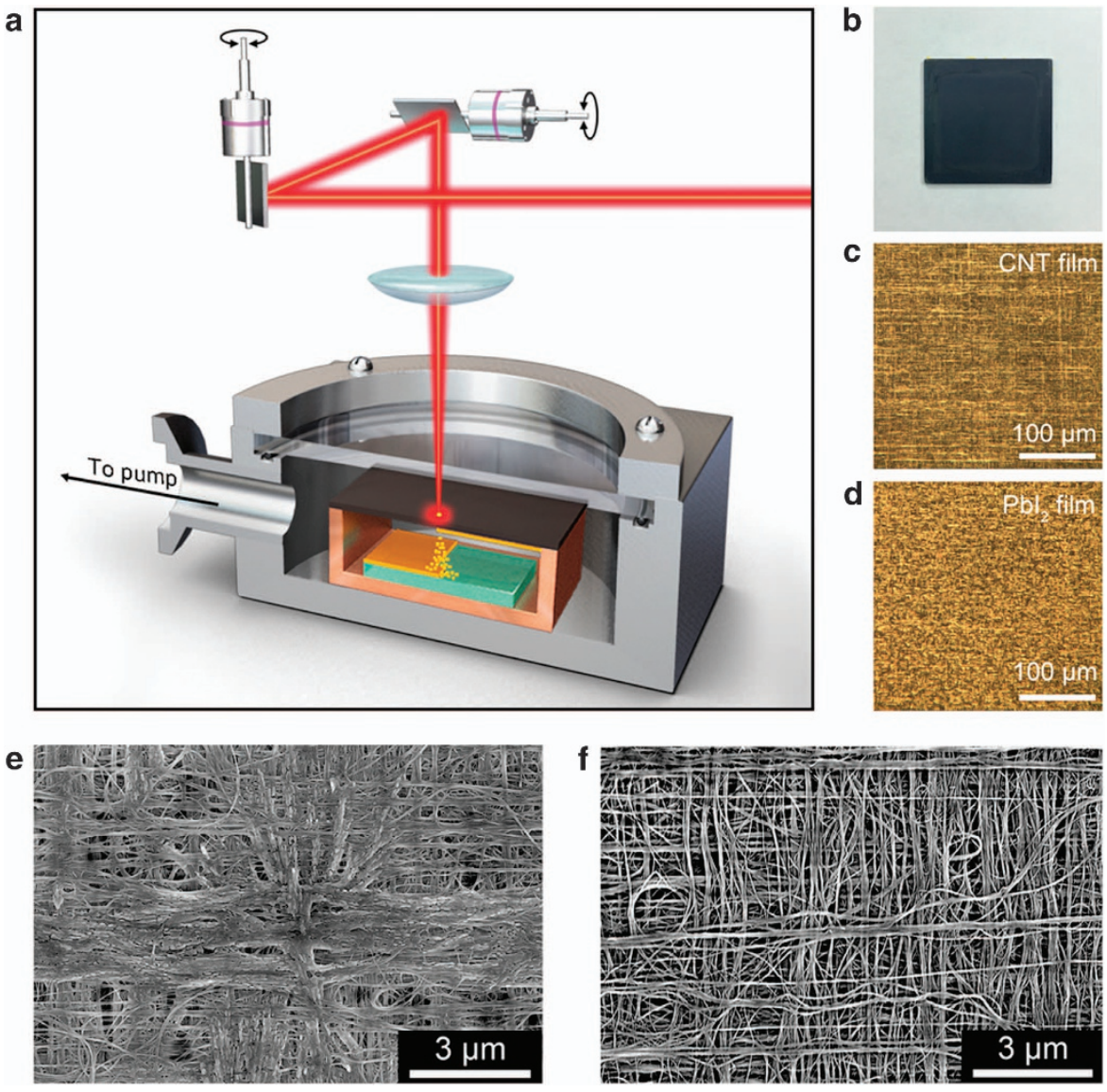

Figure 1 Illustration of the flash-evaporation printing (FEP) process and morphology of the transfer ribbon. (a) Schematic depiction of the experimental setup of the FEP. (b) Photograph of the carbon nanotube (CNT) sheet as the flash evaporator. (c, d) Optical micrographs of the CNT evaporator and the transfer ribbon. (e) Scanning electron microscopy (SEM) image of $\mathrm{Pbl}_{2}$ on the CNT films. (f) Clean CNT films without $\mathrm{Pbl}_{2}$ residue after flash evaporation.

The as-printed thin film was investigated by XRD and SEM. The $\mathrm{XRD}$ result is shown in Figure 2a. An intense peak at $12.6^{\circ}$ corresponds to the (001) diffraction peak of $\mathrm{PbI}_{2}$, validating the success of the FEP technology in printing the $\mathrm{PbI}_{2}$ film. The surface morphology of the $\mathrm{PbI}_{2}$ film was also investigated, and the SEM images at different magnifications are given in Figures $2 \mathrm{c}$ and $\mathrm{d}$. The morphology of the $\mathrm{PbI}_{2}$ film is uniform and abundant of nanoscaled grains that is obviously distinct from a solutionprocessed $\mathrm{PbI}_{2}$ film (Supplementary Figure S4), and this highly porous nanostructure is favorable for subsequent MAI penetration and perovskite synthesis.

The well-prepared $\mathrm{PbI}_{2}$ precursor allows for the fabrication of the final $\mathrm{MAPbI}_{3}$ perovskite thin film. The $\mathrm{PbI}_{2}$ film was dipped into an MAI solution ( $10 \mathrm{mg} \mathrm{ml}^{-1}$ in isopropyl alcohol). The yellow $\mathrm{PbI}_{2}$ film immediately turned dark red once the film was immersed into the MAI bath, indicating that the $\mathrm{PbI}_{2}$ film reacted with MAI efficiently. The dipping process took $10 \mathrm{~min}$, and then the in situ synthesized film was studied by SEM, XRD and UV-Vis absorption spectroscopy. The SEM images in Figures 2e and $\mathrm{f}$ show a uniform surface and a notable change of morphology induced by the MAI bath. The crystalline structure was further studied by XRD, as depicted in Figure 2a. Intense diffraction peaks at $14.1^{\circ}, 28.4^{\circ}$, and $31.8^{\circ}$ of the red plot correspond to the (110), (220), and (310) planes of the tetragonal $\mathrm{MAPbI}_{3}$ phase. $^{21,30,43}$ Moreover, the XRD pattern exhibits two extra peaks at $19.9^{\circ}$ and $24.4^{\circ}$ that were observed in the simulated perovskite XRD pattern reported by Malinkiewicz et al. ${ }^{44}$ It is noteworthy that there is only a small signature of a peak at $12.6^{\circ}\left(\mathrm{PbI}_{2}\right)$, indicating that there is little $\mathrm{PbI}_{2}$ left on the substrate. Hence, the perovskite film has a high phase purity. UV-Vis absorption spectroscopy was then used to study the characteristic absorption of the perovskite films, as given in Figure $2 \mathrm{~b}$. The two comparative absorption spectra show the prominent changes of the optical properties induced by the MAI bath. This figure also shows a band-to-band optical absorption edge at $\sim 800 \mathrm{~nm}(\sim 1.55 \mathrm{eV})$ for the $\mathrm{MAPbI}_{3}$ perovskite, with an absorption plateau at wavelengths below $500 \mathrm{~nm}^{23,45}$ The strong absorption of light indicates that the perovskite film may be promising for photovoltaic applications.

The FEP technology and the perovskite film made by the two-step strategy can be integrated into a solar cell. The details of the fabrication and characterization of the devices can be found in the Materials and Methods section. Figure 3a provides the structural diagram of the planar perovskite solar cell: an FTO glass served as a transparent electrode; a PCBM-coated $\mathrm{TiO}_{2}$ film served as an electron-transport layer; a perovskite absorber layer was derived from the printed $\mathrm{PbI}_{2}$, Spiro-OMeTAD served as the hole-transport layer and $\mathrm{Au}$ served as a back electrode. The color-enhanced cross-sectional SEM image of the device architecture is shown in Figure $3 \mathrm{c}$, where each layer can be clearly defined according to the color variation. The energy-level diagram is shown in Figure 3b. Note that PCBM is also important to achieve better electron extraction and transportation that can be examined in the comparative studies in the following experiments. Figures $3 \mathrm{~d}$ and e display the representative 

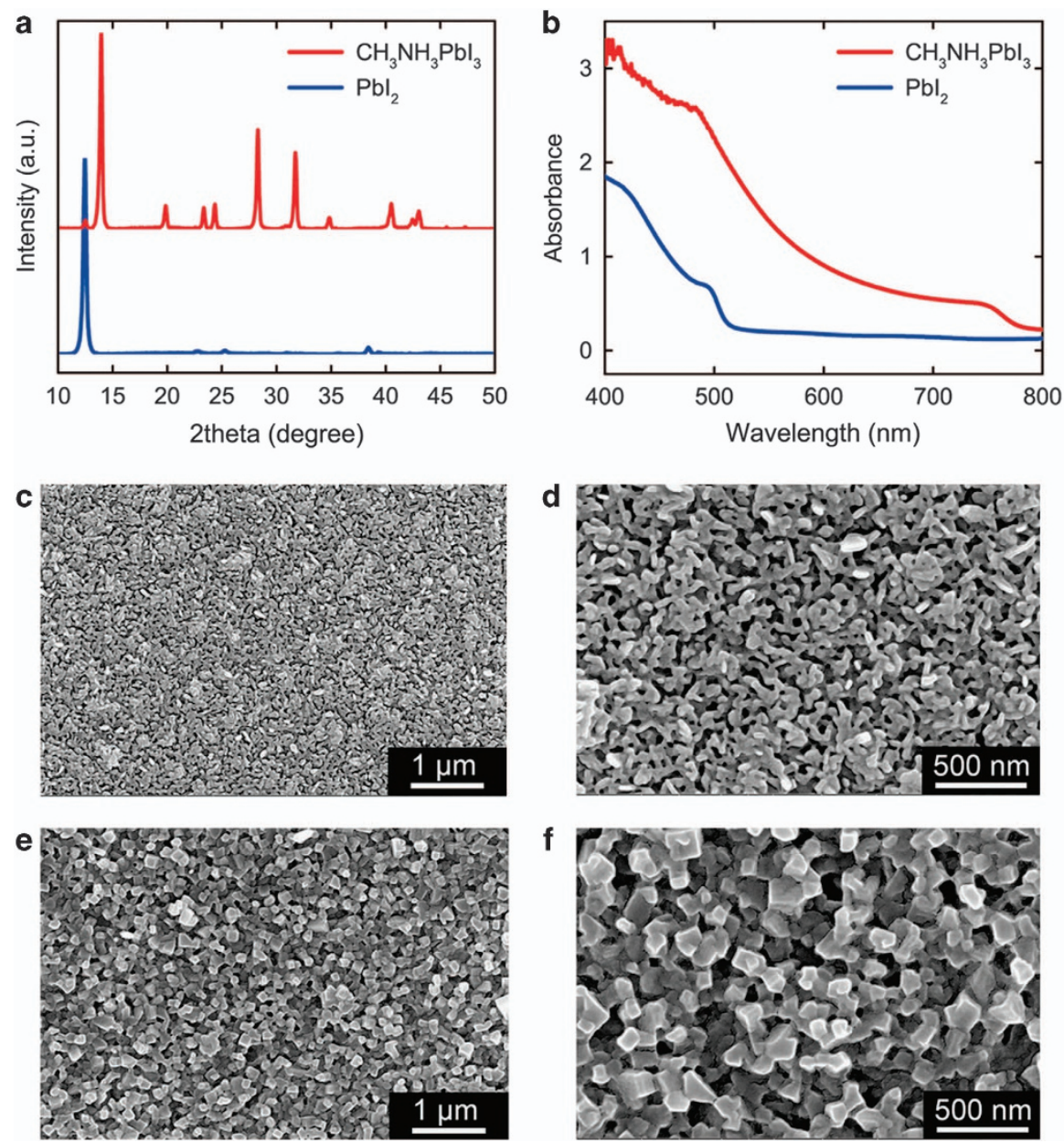

Figure 2 Characterization of the as-printed thin films. (a) X-ray diffraction (XRD) patterns and (b) ultraviolet-visible (UV-Vis) absorption spectra of the $\mathrm{Pbl}_{2}$ and $\mathrm{MAPbl}_{3}$ thin films deposited on $\mathrm{FTO} / \mathrm{TiO}_{2} / \mathrm{PCBM}$ substrates. (c, d) Scanning electron microscopy (SEM) images of the $\mathrm{Pbl}_{2}$ film deposited on an $\mathrm{FTO} / \mathrm{TiO}_{2} / \mathrm{PCBM}$ substrate. (e, f) SEM images of the perovskite film derived from the $\mathrm{Pbl}_{2}$ film dipped into methylammonium iodide (MAI) solution. FTO, fluorine-doped tin oxide; PCBM, [6,6]-phenyl-C61-butyric acid methyl ester; $\mathrm{TiO}_{2}$, titanium dioxide.

current density versus voltage $(J-V)$ characteristics and external quantum efficiency (EQE) or $\mathrm{IPCE}^{46}$ spectra of the optimized planar devices.

Hysteresis phenomena were also revealed by the forward and reverse voltage scans. Table 1 summarizes the photovoltaic parameters of these devices. The optimized device with the PCBM layer showed an open-circuit voltage $\left(V_{\mathrm{oc}}\right)$ of $0.94 \mathrm{~V}$, a short-circuit current density $\left(J_{\mathrm{sc}}\right)$ of $15.9 \mathrm{~mA} \mathrm{~cm}^{-2}$, a fill factor of $68.9 \%$ and a PCE of $10.3 \%$ in the reverse scan. In the forward scan, a PCE of $8.9 \%$ was obtained with a $V_{\mathrm{oc}}$ of $0.94 \mathrm{~V}$, a $J_{\mathrm{sc}}$ of $14.5 \mathrm{~mA} \mathrm{~cm}^{-2}$ and a fill factor of $65.3 \%$. Furthermore, the $J_{\mathrm{sc}}$ was confirmed by IPCE measurement (Figure 3e) with an integrated $J_{\mathrm{sc}}$ of $14.5 \mathrm{~mA} \mathrm{~cm}^{-2}$. The device without the PCBM layer showed a much lower PCE with pronounced hysteresis, indicating the vital role of PCBM in modifying the $\mathrm{TiO}_{2}$ /perovskite interface. ${ }^{21,47}$ Moreover, the nanostructured $\mathrm{PbI}_{2}$ precursor made by FEP showed performance advantages compared with the solutionprocessed $\mathrm{PbI}_{2}$ precursor synthesized in our lab.

The photovoltaic parameters of the best-performing device prepared starting from solution-processed $\mathrm{PbI}_{2}$ are also listed in Table 1 for comparison, and the $J-V$ characteristics of this batch of samples are provided in Supplementary Figure S5. The PCEs can be possibly improved by following the latest enhancement techniques, for example, utilizing mixed-cation perovskites and mesoporous $\mathrm{TiO}_{2}$ or performing extra solution processing to smoothen the perovskite surface. ${ }^{48}$ In addition, an optimized FEP system with an ultrahigh vacuum, a load lock and a transfer chamber will be beneficial to the printed thin films, as the materials can thus avoid exposure to active residual and air.

The as-fabricated perovskite photovoltaic devices can also be used as photodetectors. The responsivity of the device can be calculated from the IPCE spectra (Figure 3e) by the following equation: $:^{49,50}$

$$
E Q E=\frac{R_{\lambda}}{\lambda} \times \frac{h c}{e} \approx \frac{R_{\lambda}}{\lambda} \times(1240 \mathrm{~W} \cdot \mathrm{nm} / \mathrm{A})
$$

where EQE is the external quantum efficiency, also known as IPCE, $R_{\lambda}$ is the responsivity, $\lambda$ is the light wavelength in $\mathrm{nm}, h$ is Planck's constant, $c$ represents the velocity of light in a vacuum and $e$ is the elementary charge. The $R_{\lambda}$ versus $\lambda$ curves are presented in Figure $4 \mathrm{a}$. It shows that the devices with PCBM have a photoresponse from 350 to $780 \mathrm{~nm}$, suggesting that the photodetector has a wide-range photoresponse from UV to visible light. The peak responsivity was $0.31 \mathrm{~A} \mathrm{~W}^{-1}$ at a wavelength of $740 \mathrm{~nm}$, comparable to commercial large-area silicon photodiodes. ${ }^{51}$ Further experiments were performed to investigate the responses to varying degrees of input irradiance under the illumination of light with a wavelength of 
a

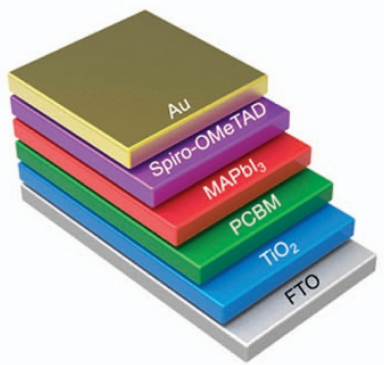

b

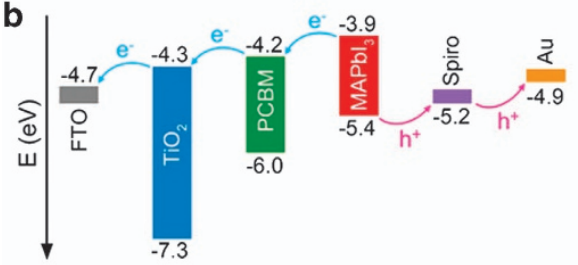

C

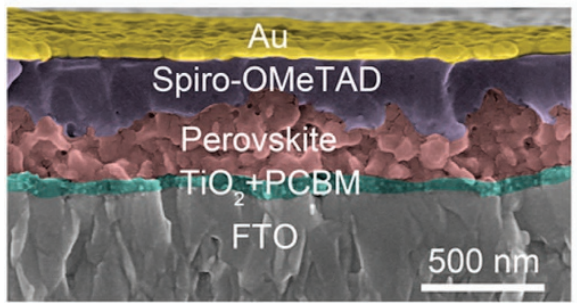

d

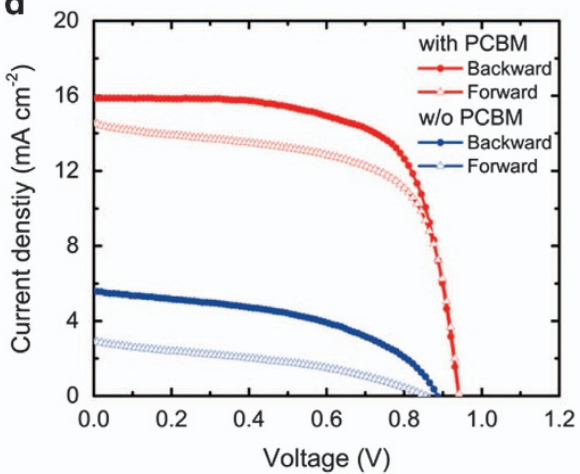

e

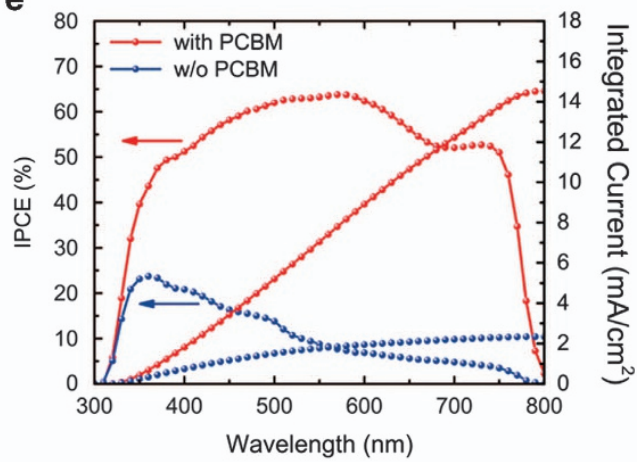

Figure 3 The structure and performances of the perovskite solar cells. (a) Structural diagram of the hybrid perovskite photovoltaic device. (b) Energy band alignment of the device stack. (c) False color cross-sectional-view scanning electron microscopy (SEM) image of a complete photovoltaic device. (d) $J-V$ curves of the best-performing devices measured at a simulated AM1.5G solar irradiation of $100 \mathrm{~mW} \mathrm{~cm}^{-2}$. (e) Incident photon-to-current efficiency (IPCE) spectra (the right-hand axis indicates the integrated photocurrent expected to be generated under AM1.5G irradiation).

Table 1 Photovoltaic parameters of the perovskite solar cells with and without PCBM interface layers

\begin{tabular}{lccccc}
\hline & Device & $\mathrm{V}_{o c}(V)$ & $\mathrm{J}_{s c}\left(m A c m^{-2}\right)$ & $F F(\%)$ & PCE (\%) \\
\hline $\mathrm{TiO}_{2} / \mathrm{PCBM}$ & Reverse scan & 0.94 & 15.9 & 68.9 & 10.3 \\
& Forward scan & 0.94 & 14.5 & 65.3 & 8.9 \\
$\mathrm{TiO}_{2}$ & Reverse scan & 0.89 & 5.6 & 48.2 & 2.4 \\
\multirow{2}{*}{ Solution-processed } & Forward scan & 0.86 & 2.9 & 36.1 & 0.9 \\
& Reverse scan & 0.93 & 16.4 & 61.3 & 9.3 \\
& Forward scan & 0.84 & 17.9 & 34.5 & 5.2 \\
\hline
\end{tabular}

Abbreviations: FF, fill factor; $J_{\text {Sc }}$, short-circuit current density; PCBM, [6,6]-phenyl-C61-butyric acid methyl ester; $\mathrm{PCE}$, power conversion efficiency; $\mathrm{TiO}_{2}$, titanium dioxide; $V_{\mathrm{oc}}$, open-circuit voltage.

$530 \mathrm{~nm}$. Figure $4 \mathrm{~b}$ shows the photocurrent versus incident light intensity plots for the devices, revealing linear responses. The linear dynamic range (LDR) can thus be calculated according to the equation of $\mathrm{LDR}=20 \log \left(J_{\mathrm{ph}}{ }^{*} / J_{\text {dark }}\right)$, where $J_{\mathrm{ph}}{ }^{*}$ is the photocurrent measured at a light intensity of $1 \mathrm{~mW} \mathrm{~cm}^{-2} .52$ The LDR exceeded $80 \mathrm{~dB}$ for the photodetector with PCBM, and this is higher than those of InGaAs photodetectors $(66 \mathrm{~dB})$. The comparative curves in Figures $4 \mathrm{a}$ and $\mathrm{b}$ also indicate that the device with PCBM performs much better. Moreover, the device functioned well in the measurement of response speed with an oscilloscope. A supercontinuum white-light source with a pulse duration $<2$ ns and a frequency of $500 \mathrm{~Hz}^{53}$ was irradiated on the device. The transient photocurrent response of the device with PCBM is shown in Figure 4c. The rise time and decay time (defined as the time to reach $90 \%$ of the maximum photocurrent from the dark current and the time to recover to $1 / \mathrm{e}$ of the maximum photocurrent, respectively ${ }^{54}$ ) were $\sim 10$ and $200 \mu$ s, respectively, agreeing well with the results in the literature. ${ }^{29,55}$ Therefore, it can be confirmed that the FEP methodology is well suited to fabricate perovskite films for solar cells and photodetectors.

The FEP technique can also be employed to print patterned thin films that is essential for printing technologies. Figure 5 shows a simple but efficient strategy to pattern perovskites with a shadow mask. The substrate was first covered by a mask with desired patterns, and then $\mathrm{PbI}_{2}$ was printed onto the mask-covered substrate with the FEP process, and finally the printed film was exposed to the MAI bath. The patterned perovskite film was thus fabricated on the substrate. The central panel illustrates a perovskite array on a flexible polyethylene terephthalate substrate. Another feasible strategy for printing patterns with FEP can be modeled from conventional printing technologies, such as ink-jet printers and impact printers. A conceptual diagram of a flash-evaporation printer is illustrated in Figure 6. The compact module integrates a transfer ribbon, shadow mask and laser. The designed pattern is point-by-point printed onto the substrate by scanning the surface with the FEP module. This printer provides a solution for the large-area fabrication of functional devices with the FEP methodology.

In addition to the printed solar cell and the efficient patterning, the FEP technology shows more advantages for the preparation of perovskite thin films. The distance between the transfer ribbon and the substrate is only $\sim 1 \mathrm{~mm}$, much smaller than that in conventional thermal evaporation. The close range can efficiently improve the $\mathrm{PbI}_{2}$ utilization during evaporation and thus effectively reduce lead pollution to the environment. It has been shown that the CNT 
a

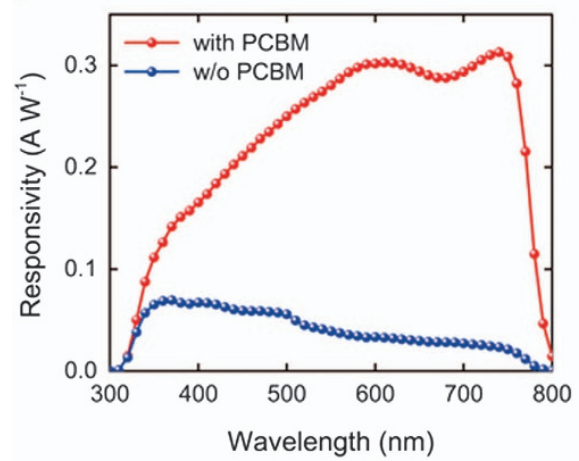

b

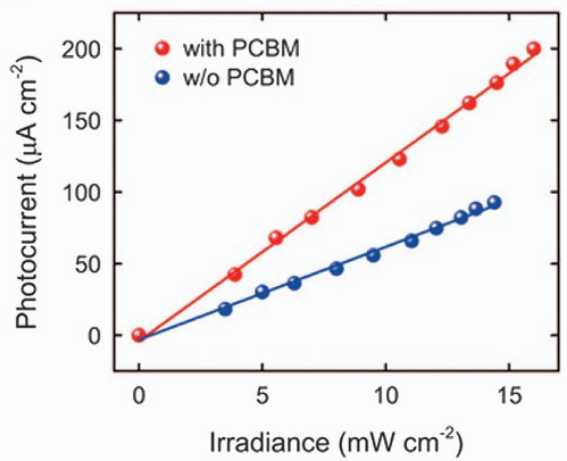

C

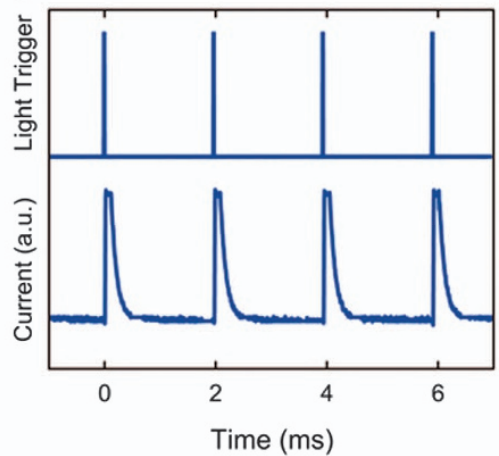

Figure 4 The properties of the perovskite photodetectors. (a) Spectral responsivity derived from the incident photon-to-current efficiency (IPCE) spectra. (b) Photocurrent linearity upon varying the $530 \mathrm{~nm}$ input irradiance. (c) Transient photocurrent response at a pulse frequency of $500 \mathrm{~Hz}$ with a device area of $0.2 \mathrm{~cm}^{2}$.

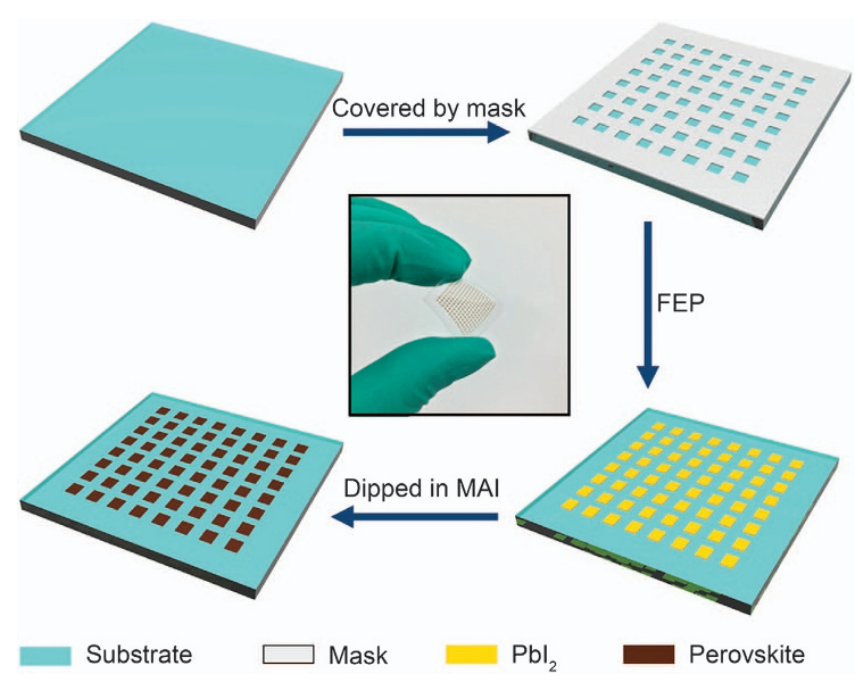

Figure 5 Schematic illustration of the deposition of regular $\mathrm{Pbl}_{2}$ arrays and the formation of patterned perovskites.

evaporator maintains a good condition after flash evaporation (Figure 1f), indicating that the CNTs can be fully reused. Furthermore, the future applications of this technology are promising. For example, FEP can be developed into a roll-to-roll strategy for mass production with low cost that is facilitated by the flexibility of the CNTs (Figure 6). Additionally, the compact geometry of the FEP dramatically simplifies the process chamber (Supplementary Figure S1) and is more cost effective than conventional evaporation facilities. The FEP chamber also provides a clean and sealed vacuum environment for the procedures compared with solution methods that is beneficial to improve the thin film quality and interlayer interface. These merits indicate that the FEP is not only environmentally friendly but also cost effective in terms of the applications of the $\mathrm{MAPbI}_{3}$ perovskite.

The FEP we developed is a distinctive technology. It allows thermalevaporation technology to evolve into a general printing solution. In addition to the $\mathrm{PbI}_{2}$ films shown here, this technology can be applied to print most other evaporation materials. Supplementary Figures S6 and S7 show patterned Tris(8-hydroxyquinolinato)aluminum $\left(\mathrm{Alq}_{3}\right)$ and $\mathrm{Au}$ thin films, demonstrating the potential to print organic light-emitting diodes and interconnecting microdevices with direct metal printing. Research on the direct printing of perovskite

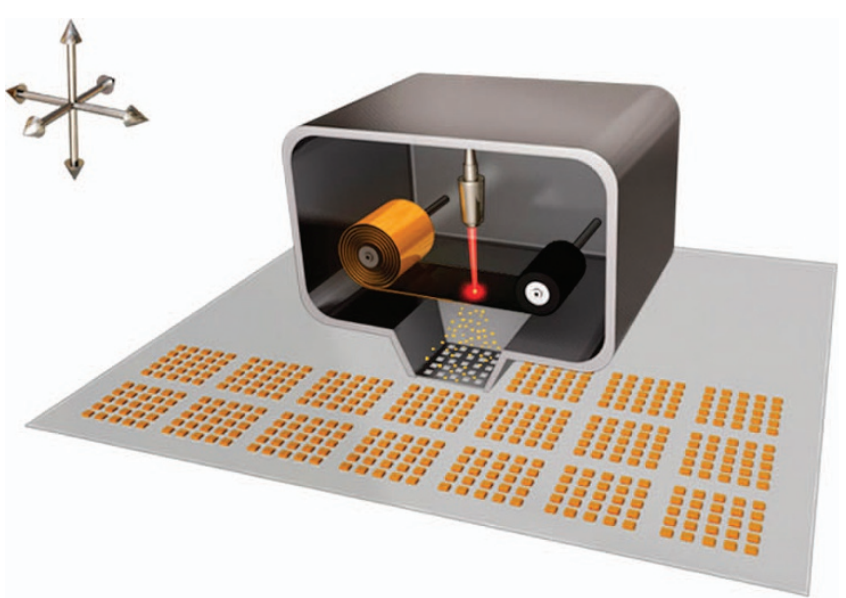

Figure $6 \mathrm{~A}$ conceptual diagram of a flash-evaporation printer. The addressable compact flash-evaporation printing (FEP) module integrates a transfer ribbon, shadow mask and laser.

thin films using an $\mathrm{MAPbI}_{3}$ transfer ribbon is also in progress, and it will be reported elsewhere in the future. It should be noted that the flash-evaporation transfer ribbons of different materials can be prepared through appropriate routes that is not limited to solution processing. Moreover, multiple stimuli can be employed by the FEP technology. In addition to lasers, the CNT evaporator can also be heated by Joule heating and hybrid heating methods. The CNT evaporator prevails over metal heaters because of its ultrasmall HCPUA and thickness. It can be heated to an elevated temperature within milliseconds. The cold end effect is also significantly reduced by the ultrathin structure, resulting in a more uniform temperature distribution (Supplementary Figure S8). The heating currents through the CNT evaporator are greatly reduced compared with metal evaporators, and this is meaningful to a compact FEP system with a Joule heating stimulus. Therefore, it is reasonable to expect the FEP to have prospective applications in a wide range of fields.

\section{CONCLUSION}

In summary, a convenient FEP technology was realized by incorporating a PVD technique and a printing method that provides an efficient approach for printing high-quality thin films. A flash- 
evaporation transfer ribbon was crucial for the success of the FEP, and it was fabricated by coating target materials on a freestanding CNT sheet that has an ultrasmall heat capacity and fast thermal response. The printing was conducted by the gas-phase transportation from the transfer ribbon to a substrate. Using the FEP technique, a novel printable solution was developed to fabricate perovskite thin films, and detailed analysis revealed that the printed $\mathrm{PbI}_{2}$ precursors and the corresponding $\mathrm{MAPbI}_{3}$ thin films had ideal crystalline structures and high qualities. The potential of the FEP was verified by its ideal integration into the fabrication process of photovoltaic devices that showed PCEs of $\sim 10.3 \%$, and these films were also utilized as photodetectors. Moreover, patterned perovskite films can also be prepared by FEP using a shadow mask or point-by-point printing technique, and the compact geometry allows for convenient scale-up for large panel applications. The FEP is a promising methodology for printing functional materials, and this technology will be of great benefit to a variety of applications in printed electronics, organic electronics and future flexible electronics.

\section{CONFLICT OF INTEREST}

The authors declare no conflict of interest.

\section{ACKNOWLEDGEMENTS}

This work was financially supported by the National Basic Research Program of China (No. 2012CB932301) and the National Natural Science Foundation of China (Nos. 51472142 and 51102147).

Author contributions: YW and KJ conceived and supervised the research. YW and HW designed the experiments. HW performed most of the experiments, including the FEP experiments, characterization and data analysis. HW and XZ fabricated the photovoltaic devices and performed the tests of the solar cells. HW and HM performed the photodetector measurements. The paper was written by HW and YW with contributions from all the co-authors.

1 Pardo, D. A., Jabbour, G. E. \& Peyghambarian, N. Application of screen printing in the fabrication of organic light-emitting devices. Adv. Mater. 12, 1249-1252 (2000).

2 Birnstock, J., Blässing, J., Hunze, A., Scheffel, M., Stößel, M., Heuser, K. Wittmann, G., Wörle, J. \& Winnacker, A. Screen-printed passive matrix displays based on light-emitting polymers. Appl. Phys. Lett. 78, 3905-3907 (2001).

3 Kashiwagi, Y., Koizumi, A., Takemura, Y., Furuta, S., Yamamoto, M., Saitoh, M., Takahashi, M., Ohno, T., Fujiwara, Y., Murahashi, K., Ohtsuka, K. \& Nakamoto, M. Direct transparent electrode patterning on layered GaN substrate by screen printing of indium tin oxide nanoparticle ink for Eu-doped GaN red light-emitting diode. Appl. Phys. Lett. 105, 223509 (2014).

4 Liu, S., Xie, J., Li, H., Wang, Y., Yang, H. Y., Zhu, T., Zhang, S., Cao, G. \& Zhao, X. Nitrogen-doped reduced graphene oxide for high-performance flexible all-solid-state micro-supercapacitors. J. Mater. Chem. A 2, 18125-18131 (2014).

5 Yan, H., Chen, Z., Zheng, Y., Newman, C., Quinn, J. R., Dotz, F., Kastler, M. \& Facchetti, A. A high-mobility electron-transporting polymer for printed transistors. Nature 457, 679-686 (2009).

6 Zschieschang, U., Klauk, H., Halik, M., Schmid, G. \& Dehm, C. Flexible organic circuits with printed gate electrodes. Adv. Mater. 15, 1147-1151 (2003).

7 Sirringhaus, H., Kawase, T., Friend, R. H., Shimoda, T., Inbasekaran, M., Wu, W. $\&$ Woo, E. P. High-resolution inkjet printing of all-polymer transistor circuits. Science 290, 2123-2126 (2000).

8 Gamerith, S., Klug, A., Scheiber, H., Scherf, U., Moderegger, E. \& List, E. J. W. Direct ink-jet printing of $\mathrm{Ag}-\mathrm{Cu}$ nanoparticle and Ag-precursor based electrodes for OFET applications. Adv. Funct. Mater. 17, 3111-3118 (2007).

9 Lee, Y., Choi, J. R., Lee, K. J., Stott, N. E. \& Kim, D. Large-scale synthesis of copper nanoparticles by chemically controlled reduction for applications of inkjet-printed electronics. Nanotechnology 19, 415604 (2008).

10 Ko, S. H., Pan, H., Grigoropoulos, C. P., Luscombe, C. K., Fréchet, J. M. J. \& Poulikakos, D. All-inkjet-printed flexible electronics fabrication on a polymer substrate by low-temperature high-resolution selective laser sintering of metal nanoparticles. Nanotechnology 18, 345202 (2007).

11 Arias, A. C., Ready, S. E., Lujan, R., Wong, W. S., Paul, K. E., Salleo, A., Chabinyc, M. L., Apte, R., Street, R. A., Wu, Y., Liu, P. \& Ong, B. All jet-printed polymer thin-film transistor active-matrix backplanes. Appl. Phys. Lett. 85, 3304-3306 (2004).
12 Xiao, L., Chen, Z., Feng, C., Liu, L., Bai, Z., Wang, Y., Qian, L., Zhang, Y., Li, Q., Jiang, K. \& Fan, S. Flexible, stretchable, transparent carbon nanotube thin film loudspeakers. Nano Lett. 8, 4539-4545 (2008).

13 Wei, Y., Lin, X., Jiang, K., Liu, P., Li, Q. \& Fan, S. Thermoacoustic chips with carbon nanotube thin yarn arrays. Nano Lett. 13, 4795-4801 (2013).

14 Wei, H., Wei, Y., Lin, X., Liu, P., Fan, S. \& Jiang, K. Ice-assisted transfer of carbon nanotube arrays. Nano Lett. 15, 1843-1848 (2015).

15 Harris, L. \& Siegel, B. M. A method for the evaporation of alloys. J. Appl. Phys. 19, 739-741 (1948).

16 Richards, J. L., Hart, P. B. \& Gallone, L. M. Epitaxy of compound semiconductors by flash evaporation. J. Appl. Phys. 34, 3418-3420 (1963).

17 Longo, G., Gil-Escrig, L., Degen, M. J., Sessolo, M. \& Bolink, H. J. Perovskite solar cells prepared by flash evaporation. Chem. Commun. 51, 7376-7378 (2015).

18 Lee, M. M., Teuscher, J., Miyasaka, T., Murakami, T. N. \& Snaith, H. J. Efficient hybrid solar cells based on meso-superstructured organometal halide perovskites. Science 338, 643-647 (2012).

19 Loi, M. A. \& Hummelen, J. C. Hybrid solar cells: perovskites under the sun. Nat. Mater. 12, 1087-1089 (2013).

20 Hodes, G. Perovskite-based solar cells. Science 342, 317-318 (2013).

21 Jeng, J. Y., Chiang, Y. F., Lee, M. H., Peng, S. R., Guo, T. F., Chen, P. \& Wen, T. C. $\mathrm{CH}_{3} \mathrm{NH}_{3} \mathrm{Pbl}_{3}$ perovskite/fullerene planar-heterojunction hybrid solar cells. Adv. Mater. 25, 3727-3732 (2013).

22 Stoumpos, C. C., Malliakas, C. D. \& Kanatzidis, M. G. Semiconducting tin and lead iodide perovskites with organic cations: phase transitions, high mobilities, and near-infrared photoluminescent properties. Inorg. Chem. 52, 9019-9038 (2013).

23 Stranks, S. D., Eperon, G. E., Grancini, G., Menelaou, C., Alcocer, M. J. P., Leijtens, T., Herz, L. M., Petrozza, A. \& Snaith, H. J. Electron-hole diffusion lengths exceeding 1 micrometer in an organometal trihalide perovskite absorber. Science 342 341-344 (2013).

24 Xing, G., Mathews, N., Sun, S., Lim, S. S., Lam, Y. M., Grätzel, M., Mhaisalkar, S. \& Sum, T. C. Long-range balanced electron- and hole-transport lengths in organicinorganic $\mathrm{CH}_{3} \mathrm{NH}_{3} \mathrm{Pbl}_{3}$. Science 342, 344-347 (2013).

25 Gao, P., Gratzel, M. \& Nazeeruddin, M. K. Organohalide lead perovskites for photovoltaic applications. Energy Environ. Sci. 7, 2448-2463 (2014).

26 Xing, G., Mathews, N., Lim, S. S., Yantara, N., Liu, X., Sabba, D., Grätzel, M., Mhaisalkar, S. \& Sum, T. C. Low-temperature solution-processed wavelength-tunable perovskites for lasing. Nat. Mater. 13, 476-480 (2014).

27 Zhou, H., Chen, Q., Li, G., Luo, S., Song, T. B., Duan, H. S., Hong, Z., You, J., Liu, Y. $\&$ Yang, Y. Interface engineering of highly efficient perovskite solar cells. Science $\mathbf{3 4 5}$, 542-546 (2014).

28 Dou, L., Yang, Y., You, J., Hong, Z., Chang, W. H., Li, G. \& Yang, Y. Solution-processed hybrid perovskite photodetectors with high detectivity. Nat. Commun. 5, 5404 (2014).

29 Lian, Z., Yan, Q., Lv, Q., Wang, Y., Liu, L., Zhang, L., Pan, S., Li, Q., Wang, L. \& Sun, J. High-performance planar-type photodetector on (100) facet of $\mathrm{MAPbl}_{3}$ single crystal. Sci. Rep. 5, 16563 (2015).

30 Burschka, J., Pellet, N., Moon, S. J., Humphry-Baker, R., Gao, P., Nazeeruddin, M. K. \& Gratzel, M. Sequential deposition as a route to high-performance perovskitesensitized solar cells. Nature 499, 316-319 (2013).

31 Tu, Y., Wu, J., He, X., Guo, P., Wu, T., Luo, H., Liu, Q., Wang, K., Lin, J., Huang, M., Huang, Y., Lan, Z. \& Li, S. Solvent engineering for forming stonehenge-like $\mathrm{Pbl}_{2}$ nano-structures towards efficient perovskite solar cells. J. Mater. Chem. A 5, 4376-4383 (2017).

32 Zhang, T., Yang, M., Zhao, Y. \& Zhu, K. Controllable sequential deposition of planar $\mathrm{CH}_{3} \mathrm{NH}_{3} \mathrm{Pbl}_{3}$ perovskite films via adjustable volume expansion. Nano Lett. 15 3959-3963 (2015).

33 Zhang, H., Mao, J., He, H., Zhang, D., Zhu, H. L., Xie, F., Wong, K. S., Grätzel, M. \& Choy, W. C. H. A smooth $\mathrm{CH}_{3} \mathrm{NH}_{3} \mathrm{Pbl}_{3}$ film via a new approach for forming the $\mathrm{PbI}_{2}$ nanostructure together with strategically high $\mathrm{CH}_{3} \mathrm{NH}_{3} \mathrm{l}$ concentration for high efficient planar-heterojunction solar cells. Adv. Energy Mater. 5, 1501354 (2015).

34 Li, M., Yan, X., Kang, Z., Liao, X., Li, Y., Zheng, X., Lin, P., Meng, J. \& Zhang, Y. Enhanced efficiency and stability of perovskite solar cells via anti-solvent treatment in two-step deposition method. ACS Appl. Mater. Interf. 9, 7224-7231 (2017).

35 Ng, A., Ren, Z., Shen, Q., Cheung, S. H., Gokkaya, H. C., Bai, G., Wang, J., Yang, L., So, S. K., Djurisic, A. B., Leung, W. W. F., Hao, J., Chan, W. K. \& Surya, C. Efficiency enhancement by defect engineering in perovskite photovoltaic cells prepared using evaporated $\mathrm{Pbl}_{2} / \mathrm{CH}_{3} \mathrm{NH}_{3}$ I multilayers. J. Mater. Chem. A 3, 9223-9231 (2015).

36 Remeika, M., Raga, S. R., Zhang, S. \& Qi, Y. Transferrable optimization of spray-coated $\mathrm{Pbl} 2$ films for perovskite solar cell fabrication. J. Mater. Chem. A 5, 5709-5718 (2017).

37 Li, S., Jiang, K., Su, M., Cui, X., Huang, J., Zhang, Q., Zhou, X., Yang, L. \& Song, Y. Inkjet printing of $\mathrm{CH}_{3} \mathrm{NH}_{3} \mathrm{Pbl}_{3}$ on a mesoscopic $\mathrm{TiO}_{2}$ film for highly efficient perovskite solar cells. J. Mater. Chem. A 3, 9092-9097 (2015).

38 Wei, Z., Chen, H., Yan, K. \& Yang, S. Inkjet printing and instant chemical transformation of a $\mathrm{CH}_{3} \mathrm{NH}_{3} \mathrm{Pbl}_{3} /$ nanocarbon electrode and interface for planar perovskite solar cells. Angew. Chem. Int. Ed. 53, 13239-13243 (2014).

39 Jiang, K., Li, Q. \& Fan, S. Nanotechnology: spinning continuous carbon nanotube yarns. Nature 419, 801-801 (2002).

40 Jiang, K., Wang, J., Li, Q., Liu, L., Liu, C. \& Fan, S. Superaligned carbon nanotube arrays, films, and yarns: a road to applications. Adv. Mater. 23, 1154-1161 (2011).

41 Liu, P., Jiang, K., Liu, M., Li, Q., Fan, S. \& Sun, J. Polarized incandescent light emission from carbon nanotubes. Appl. Phys. Lett. 82, 1763-1765 (2003). 
42 Liu, P., Wei, Y., Jiang, K., Sun, Q., Zhang, X., Fan, S., Zhang, S., Ning, C. \& Deng, J. Thermionic emission and work function of multiwalled carbon nanotube yarns. Phys. Rev. B 73, 235412 (2006).

43 Liu, M., Johnston, M. B. \& Snaith, H. J. Efficient planar heterojunction perovskite solar cells by vapour deposition. Nature 501, 395-398 (2013).

44 Malinkiewicz, O., Yella, A., Lee, Y. H., Espallargas, G. M., Graetzel, M., Nazeeruddin, M. K. \& Bolink, H. J. Perovskite solar cells employing organic charge-transport layers. Nat. Photon. 8, 128-132 (2014).

45 Xiao, Z., Bi, C., Shao, Y., Dong, Q., Wang, Q., Yuan, Y., Wang, C., Gao, Y. \& Huang, J. Efficient, high yield perovskite photovoltaic devices grown by interdiffusion of solution-processed precursor stacking layers. Energy Environ. Sci. 7, 2619-2623 (2014).

46 Shaheen, S. E., Brabec, C. J., Sariciftci, N. S., Padinger, F., Fromherz, T. \& Hummelen, J. C. $2.5 \%$ efficient organic plastic solar cells. Appl. Phys. Lett. 78, 841-843 (2001).

47 Xing, G., Wu, B., Chen, S., Chua, J., Yantara, N., Mhaisalkar, S., Mathews, N. \& Sum, T. C. Interfacial electron transfer barrier at compact $\mathrm{TiO}_{2} / \mathrm{CH}_{3} \mathrm{NH}_{3} \mathrm{Pbl}_{3}$ heterojunction. Small 11, 3606-3613 (2015).

48 Bi, D., Yi, C., Luo, J., Décoppet, J.-D., Zhang, F., Zakeeruddin, Shaik, M., Li, X., Hagfeldt, A. \& Grätzel, M. Polymer-templated nucleation and crystal growth of perovskite films for solar cells with efficiency greater than $21 \%$. Nat. Energy 1 , 16142 (2016).

49 Rogalski, A., Adamiec, K. \& Rutkowski, J. Narrow-Gap Semiconductor Photodiodes (SPIE Press, 2000).

$50 \mathrm{Wu}$, J. M. \& Chang, W. E. Ultrahigh responsivity and external quantum efficiency of an ultraviolet-light photodetector based on a single $\mathrm{VO}_{2}$ microwire. ACS Appl. Mater. Interf. 6, 14286-14292 (2014).

51 Bisi, O., Campisano, S. \& Pavesi, L. Silicon-Based Microphotonics: From Basics to Applications (IOS Press, Bologna, 1999).
52 Gong, X., Tong, M., Xia, Y., Cai, W., Moon, J. S., Cao, Y., Yu, G., Shieh, C. L., Nilsson, B. \& Heeger, A. J. High-detectivity polymer photodetectors with spectral response from $300 \mathrm{~nm}$ to $1450 \mathrm{~nm}$. Science 325, 1665-1667 (2009).

53 Wu, W., Yue, J., Lin, X., Li, D., Zhu, F., Yin, X., Zhu, J., Wang, J., Zhang, J., Chen, Y., Wang, X., Li, T., He, Y., Dai, X., Liu, P., Wei, Y., Wang, J., Zhang, W., Huang, Y., Fan, L., Zhang, L., Li, Q., Fan, S. \& Jiang, K. True-color real-time imaging and spectroscopy of carbon nanotubes on substrates using enhanced Rayleigh scattering. Nano Res. 8, 2721-2732 (2015).

54 Xie, Y., Wei, L., Li, Q., Wei, G., Wang, D., Chen, Y., Jiao, J., Yan, S., Liu, G. \& Mei, L. Self-powered solid-state photodetector based on $\mathrm{TiO}_{2}$ nanorod/Spiro-MeOTAD heterojunction. Appl. Phys. Lett. 103, 261109 (2013).

$55 \mathrm{Hu}$, X., Zhang, X., Liang, L., Bao, J., Li, S., Yang, W. \& Xie, Y. High-performance flexible broadband photodetector based on organolead halide perovskite. Adv. Funct. Mater. 24, 7373-7380 (2014).

(c) (i) This work is licensed under a Creative Commons Attribution 4.0 International License. The images or other third party material in this article are included in the article's Creative Commons license, unless indicated otherwise in the credit line; if the material is not included under the Creative Commons license, users will need to obtain permission from the license holder to reproduce the material. To view a copy of this license, visit http:// creativecommons.org/licenses/by/4.0/

(C) The Author(s) 2017

Supplementary Information accompanies the paper on the NPG Asia Materials website (http://www.nature.com/am) 